\title{
Novel Modular Multiple-Input Bidirectional DC-DC Power Converter (MIPC)
}

\author{
Andrew Hintz, Udupi. R. Prasanna, Member IEEE and Kaushik Rajashekara, Fellow IEEE \\ Electrical Engineering, \\ University of Texas at Dallas \\ Richardson, Texas 75080, USA.
}

\begin{abstract}
This paper proposes a novel multiple-input bidirectional DC-DC power converter to interface more than two de sources of different voltage levels. This finds applications in distributed energy resources (DER), micro grid, and hybrid electric/fuel cell vehicles, where different dc sources of unequal voltage levels need to be connected with bidirectional power flow capability. Converter can be used to operate in both the buck and boost modes with bidirectional power control. It is also possible to independently control power flow when more than two sources are actively transferring power in either direction. This paper presents a power converter topology based on three switching legs of a standard 3-phase inverter module. The operation, analysis and design of the converter are presented with different modes of power transfer. Proposed converter is demonstrated for fuel cell vehicle application using real-time hardware-in-the-loop system. Results for a $5 \mathrm{~kW}$ system are presented validating the theoretical analysis.
\end{abstract}

Keywords - Distributed Energy Resources (DER), Micro grid, Hybrid Electric/Fuel Cell Vehicles, Multiple Input Converter, DC-DC converter, Battery, Ultracapacitor.

\section{INTRODUCTION}

In a system like micro grid, different sources like diesel generator, fuel cell, solar photovoltaic (PV), and energy storage systems like battery or ultracapacitor need to be interfaced to three phase grid or to the load. Power conditioning circuitry is necessary to match the differences in voltages from these sources and storage systems. This also serves the purpose of control of power flow to achieve maximum power point tracking and strategies for energy storage system. A block diagram of such a system is shown in Fig. 1. Energy source could be PV, wind, fuel cell, or diesel generator supplying power to the dc link of the inverter through a power converter. Bidirectional power converter is necessary to assimilate energy storage like battery and ultracapacitors with the rest of the system to interface with the grid.

A number of topologies are proposed in literature [1-9] to transfer the power from one source to another in HEV and microgrid applications. In [1], multiple sources are interfaced at a common high-frequency transformer where each source is connected through full-bridge cells utilizing twelve switches for three sources. Both phase shift and duty ratio modulations are suggested. Similar operation is proposed with a half bridge circuit at each source in [2] with half the number of switches and supplementary capacitors. In order to reduce the ripple current in the battery, current-fed half-bridge topology has been proposed in [3] with the phase shift modulation. Similarly multiple input isolated buck-boost and forward converters along with the stability analysis have been presented in [4]. All these bidirectional converters have galvanic isolation and are coupled together magnetically. Energy sharing between various sources is difficult to control in these types of topologies, although isolation gives better safety and more flexibility in selecting voltage levels. In non-isolated topology presented in [5], the battery and the ultracapacitor are cascaded using a bidirectional converter, which is connected in parallel to the fuel cell supplying a load. This does not provide the flexibility to vary the voltage across battery and ultracapacitor as they are connected directly across the fuel cell. Multiple bidirectional boost converters with various voltage sources are connected in parallel with output connected to common dc link to supply the inverter [6-8]. Voltages from several sources are boosted to dc link voltage with independent control of individual current delivered to the load. Similarly, regenerative energy is shared between the storages during braking. Voltage levels of input auxiliary sources are limited to below dc link voltage because it can only boost the input voltages and number of inductors required is equal to number of sources. Instead of additional dc-dc converter, $\mathrm{Z}$-source (LC) network is used to interface fuel cell and battery in Z-source inverter topology [9]. Although this topology is suitable with optimal devices and components, number of voltage sources is limited to two and unable to extend this topology for multiple sources.

Disadvantage of most of these topologies is the difficulty in independent transfer of power between any two sources with wide variation in voltage levels. Few of the topologies have problems in scaling it to multiple sources. Hence, this paper proposes a multi-input power converter with the following characteristics:

(a) It is possible to interface more than two $d c$ sources of different voltage levels and can be extended to any number of sources,

(b) Ability to transfer power in both directions i.e. bidirectional power flow capability,

(c) It is possible to control power flow between any two of the sources independently, and

(d) It is simpler to design, implement and control.

The topology shown in Fig. 2 can be built by connecting a switching leg with the sources through an inductor and a switching leg for each source. In order to interface a larger number of sources, connecting an 
additional inductor and switching leg for each additional source can extend the topology. Although a similar topology is presented in [10], this paper presents detailed analysis and operation during all possible conditions. In addition, this topology has been extended to operate the converter over wide voltage levels. In [10], power flow between only two of the sources is demonstrated operating in boost mode from the battery/ultracapacitor to the dc link and buck mode in opposite direction.

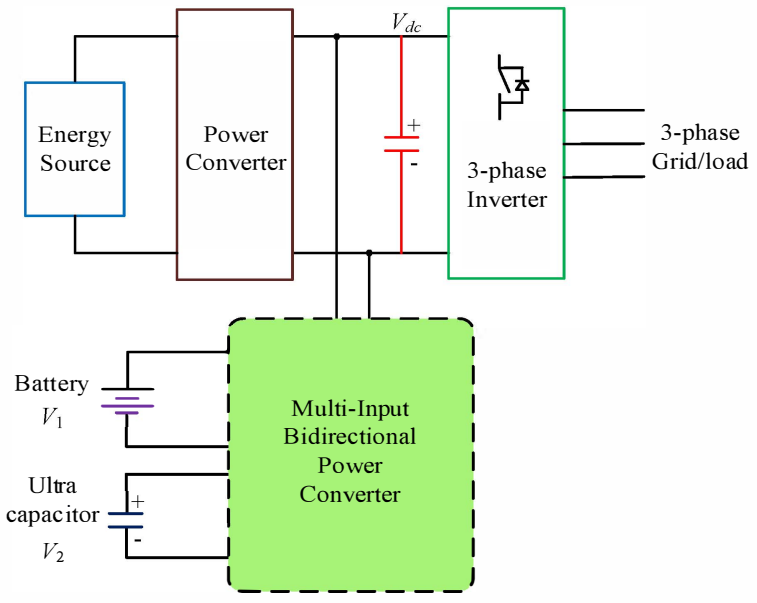

Fig. 1: Block diagram showing application of multiple-input bidirectional converter.

The objective of this paper is to present the operation and steady state analysis of the proposed converter topology. The mode-by-mode operation of the converter is explained. The design procedure of the converter is presented. Analysis and design details for various modes of operation have been verified for a $5 \mathrm{~kW}$ system using a real-time emulator based on Typhoon HIL-400.

\section{OPERATION AND ANALYSIS OF THE CONVERTER}

The proposed topology consists of a standard threephase inverter modified by adding two high frequency inductors as shown in Fig. 2.

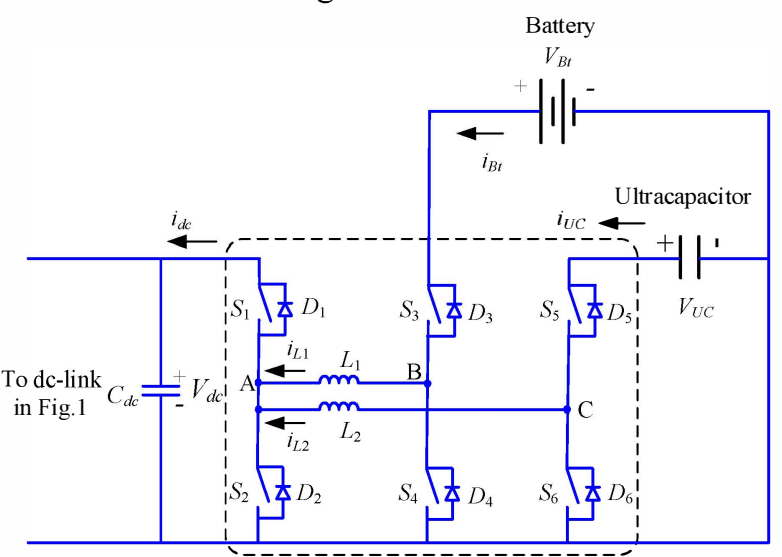

Fig. 2. Schematic of the proposed multiple-input bidirectional converter topology.

In the block diagram, sources $V_{B t}$ and $V_{U C}$ represents energy storage system like battery and ultracapacitor, which are interfaced with the dc link of inverter $V_{d c}$. Two legs of switch modules are connected to the DC voltage sources instead of dc bus. Another leg of the converter is connected to the dc link of the inverter, which is also fed by energy source through a dc-dc converter. If necessary more power/energy sources can be added by adding additional legs to the inverter. Operation of the converter under these modes of operation is discussed in the following sections.

\section{A. Battery and Dc Link}

In this mode of operation, energy stored in battery is transferred to dc link to supply load/grid. Switching sequence in this mode of operation is given in Table I. Inductor $L_{1}$, connecting battery and dc link is storing energy from battery at first time interval $T_{1}$ by turning-on switches $S_{2}$ and $S_{3}$. Battery voltage $V_{B t}$ appears across $L_{1}$ resulting in increase of current with a slope of $V_{B l} / L_{1}$. During time interval $T_{2}$ both the switches are turned-off. Inductor current $i_{L 1}$, flows to dc link capacitor by forward biasing diodes $D_{1}$ and $D_{4}$. Energy stored in $L_{1}$ during time $T_{1}$ is being discharged to $C_{d c}$ in this interval with a negative slope of $V_{d c} / L_{1}$. The flow of current through these diodes results in a voltage drop of around $1 \mathrm{~V}-1.2 \mathrm{~V}$ each. In the next time interval $T_{3}$, switches $S_{1}$ and $S_{4}$ are turned-on. Current continues to flow from $L_{1}$ to the dc link through the switches as opposed to the diodes in $T_{2}$. Switches $S_{1}$ and $S_{4}$ are made to operate as synchronous rectifier resulting in a reduced voltage drop to a level of around $0.2 \mathrm{~V}$, thereby improving system efficiency.

Under steady state operation, relation between dc link voltage and battery voltage is given by,

$$
V_{d c}=\frac{T_{1}}{T_{2}+T_{3}} \cdot V_{B t}=\frac{D}{1-D} \cdot V_{B t}
$$

Where, $D$ is the duty ratio defined by $T_{1} / T_{S}$. $T_{S}$ is the time period of switching cycle, which is total of all three time intervals. If battery voltage $V_{B t}$ is less than the dc link voltage $V_{d c}$, the converter boosts $V_{B t}$ to $V_{d c}$ by operating at $D>0.5$. If battery voltage $V_{B t}$ is greater than dc link voltage $V_{d c}$, the converter charges the battery from dc link by operating at $\mathrm{D}<0.5$. The switching sequence for this operation is given in mode A(ii) of Table I. Principle of energy transfer remains the same; energy is stored in $L_{1}$ in interval $T_{1}$ and used to charge the battery in intervals $T_{2}$ and $T_{3}$. Considering duty ratio $D$ to be $T_{1} / T_{S}$, the relation between two voltages is given in (2).

$$
V_{B t}=\frac{T_{1}}{T_{2}+T_{3}} \cdot V_{d c}=\frac{D}{1-D} \cdot V_{d c}
$$

\section{B. Ultracapacitor and Dc Link}

Energy transfer from ultracapacitor to the dc link is explained in this subsection where voltage level of ultracapacitor needs to be boosted to the higher dc link voltage. Switching sequence for three distinct time intervals of operation is given in mode B(i) in Table I. For the time duration $T_{1}$, inductor $L_{2}$ is charged by the ultracapacitor by triggering the switches $S_{2}$ and $S_{5}$ while the remaining switches are turned off. Current $i_{L 2}$, increases linearly with a slope of $V_{U C} / L_{2}$. Once inductor $L_{2}$ is charged for a predetermined time, both the switches $S_{2}$ and $S_{5}$ are turned off resulting in conduction of diodes 
$D_{1}$ and $D_{6}$. Energy stored in the inductor $L_{2}$ by the ultracapacitor is being utilized to charge the dc link capacitance and hence to supply the load. Since, voltage drop across these diodes are higher, corresponding MOSFETs $S_{1}$ and $S_{6}$ are turned on in the time interval $T_{3}$. This effectively makes it a synchronous rectifier with reduced voltage drop subsequently reducing the losses in the converter. Voltages $V_{d c}$ and $V_{U C}$ are related by duration of these three time intervals and it can be calculated using (3).

$$
V_{d c}=\frac{T_{1}}{T_{2}+T_{3}} \cdot V_{U C}=\frac{D}{1-D} \cdot V_{U C}
$$

In a hybrid vehicle system, ultracapacitor voltage $V_{U C}$ is generally kept smaller than $V_{d c}$. However, this converter enables to interface two sources without changing the topology even though one voltage is either higher or lower than the other just by varying duty ratio $D$. Whenever, ultracapacitor needs to be charged from dc link, similar devices are switched as given in mode B(ii) in Table I. Direction of current flow in inductor $L_{2}$ is opposite to that of mode $\mathrm{B}(\mathrm{i})$, as the direction of power flow is now reversed. In this mode, it is important to observe the changes in switching devices in three different time intervals. Considering duty ratio $D$ to be $T_{1} / T_{S}$, the relation between two voltages is given in (4).

$$
V_{U C}=\frac{T_{1}}{T_{2}+T_{3}} \cdot V_{d c}=\frac{D}{1-D} \cdot V_{d c}
$$

In order to charge the ultracapacitor from dc link that is at higher voltage, converter is operated at $D<0.5$.

\section{Battery and Ultracapacitor}

Whenever, energy stored in the battery needs to be transferred over to the ultracapacitor or vice versa, switching sequence given in Table I is followed. There are various permutations possible by switching four switches $S_{3}$ to $S_{6}$, depending on the voltage levels of the two energy sources. While charging the ultracapacitor from the battery in mode $\mathrm{C}(\mathrm{i})$, converter can be operated in boost mode, buck mode, or buck-boost mode. Boost mode of operation is given where ripple in the battery current is smaller as compared to other two modes. This is chosen to improve the life of battery by reducing the peak value of charging or discharging current. If the ultracapacitor voltage is lower than the battery voltage, then buck mode can be adopted. During the process of charging of ultracapacitor, if its voltage increases from less than $V_{B t}$ to above $V_{B t}$, then the controller needs to be seamlessly maneuvered from buck mode to boost mode of operation. On the other hand, buck-boost mode can be implemented simplifying the control by changing the value of duty ratio. Switching states given in Table I, the battery voltage is being boosted to charge the ultracapacitor. In this mode of operation, both the inductors $L_{1}$ and $L_{2}$ are storing energy during interval $T_{1}$ from the battery through switches $S_{3}$ and $S_{6}$. At the end of this interval, switch $S_{6}$ is turned-off forcing the inductor current to flow through diode $D_{5}$ to charge the ultracapacitor. To decrease the voltage drop across $D_{5}$, switch $S_{5}$ is gated on in the subsequent time interval $T_{3}$ operating as synchronous rectifier. Relation between the two voltages are given as,

$$
V_{U C}=\frac{T_{S}}{T_{2}+T_{3}} \cdot V_{B t}=\frac{1}{1-D} \cdot V_{B t}
$$

Where, $D$ is the duty ratio defined by $T_{1} / T_{S}$. In a similar operation, energy can be transferred from the ultracapacitor to the battery by switching same set of active switches $S_{3}, S_{5}$ and $S_{6}$ but with different on-time durations resulting in opposite direction of current through the inductors as compared to mode C(i). Energy transferred from the ultracapacitor to the battery depends on the time duration $T_{1}$ for which switch $S_{5}$ is retained ON given by,

$$
V_{B t}=\frac{T_{1}}{T_{S}} \cdot V_{U C}=D \cdot V_{U C}
$$

It is clear from the above equation that the energy can be transferred in this mode only if $V_{B t}$ is smaller than $V_{U C}$. If this condition is not met, then different mode of operation like boost or buck-boost can be used to control the switches without changing the circuit topology.

TABLE I CONDUCTION OF DEVICES IN DIFFERENT TIME INTERVALS OF THE

\begin{tabular}{||c|c|c|c||}
\hline \multicolumn{1}{c|}{} & $\boldsymbol{T}_{\mathbf{1}}$ & $\boldsymbol{T}_{\mathbf{2}}$ & $\boldsymbol{T}_{\mathbf{3}}$ \\
\hline \hline Mode A(i) & $S_{2}, S_{3}$ & $D_{4}, D_{1}$ & $S_{1}, S_{4}$ \\
\hline Mode A(ii) & $S_{1}, S_{4}$ & $D_{2}, D_{3}$ & $S_{2}, S_{3}$ \\
\hline Mode B(i) & $S_{2}, S_{5}$ & $D_{6}, D_{1}$ & $S_{1}, S_{6}$ \\
\hline Mode B(ii) & $S_{1}, S_{6}$ & $D_{2}, D_{5}$ & $S_{2}, S_{5}$ \\
\hline Mode C(i) & $S_{3}, S_{6}$ & $D_{5}, S_{3}$ & $S_{5}, S_{3}$ \\
\hline Mode C(ii) & $S_{5}, S_{3}$ & $D_{6}, S_{3}$ & $S_{3}, S_{6}$ \\
\hline
\end{tabular}

\section{Battery and Ultracapacitor to Dc Link}

During peak power demand from the load/grid, battery unit and ultracapacitor provide the peak power demand due to its faster dynamic response as compared with the energy source like fuel cell system. In fuel cell vehicles, the auxiliary sources have to deliver rated power during the process of cold startup of the fuel cell system.

TABLE II. CONDUCTION OF DEVICES IN DIFFERENT TIME INTERVALS WHEN ALL THE THREE SOURCES/LOADS ARE ACTIVE

\begin{tabular}{||c|c||c||c||c||c|}
\hline & $\boldsymbol{T}_{\mathbf{1}}$ & $\boldsymbol{T}_{\mathbf{2}}$ & $\boldsymbol{T}_{\mathbf{3}}$ & $\boldsymbol{T}_{\mathbf{4}}$ & $\boldsymbol{T}_{\mathbf{5}}$ \\
\hline \hline \multirow{2}{*}{ Mode D } & $\begin{array}{c}S_{2}, S_{3}, \\
S_{5}\end{array}$ & $\begin{array}{c}S_{2}, D_{4}, \\
S_{5}\end{array}$ & $\begin{array}{c}S_{2}, S_{4}, \\
S_{5}\end{array}$ & $\begin{array}{c}D_{1}, S_{4}, \\
D_{6}\end{array}$ & $\begin{array}{c}S_{1}, S_{4} \\
S_{6}\end{array}$ \\
\hline Mode E & $\begin{array}{c}S_{1}, S_{3}, \\
S_{5}\end{array}$ & $\begin{array}{c}D_{2}, S_{3}, \\
S_{5}\end{array}$ & $\begin{array}{c}S_{2}, S_{3}, \\
S_{5}\end{array}$ & $\begin{array}{c}S_{2}, S_{4}, \\
S_{5}\end{array}$ & $\begin{array}{c}S_{1}, D_{3}, \\
S_{5}\end{array}$ \\
\hline
\end{tabular}

Switching states during this mode of operation is given in Table II dividing the switching cycle $T_{S}$ into five time intervals. Identical gate signals are given to switches $S_{1}$ and $S_{6}$ with a duty ratio of $d_{2}$ and complementary of this signal is being provided to switches $S_{2}$ and $S_{5}$ as demonstrated in Fig. 3. Gate signal for the switch $S_{3}$ is synchronized with that of switch $S_{1}$ having duty ratio of 
$d_{1} . S_{4}$ is switched complementary to switch $S_{3}$ with a dead time.

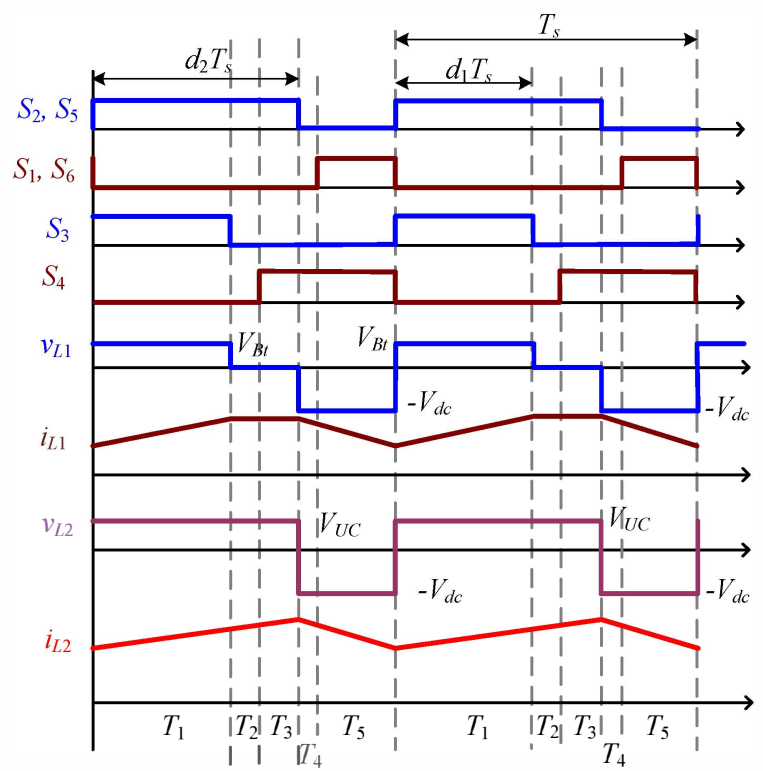

Fig. 3. Steady-state waveforms for mode D.

During interval $T_{1}$, switches $S_{2}, S_{3}$ and $S_{5}$ are gated-on charging both the inductors $L_{1}$ and $L_{2}$ by corresponding sources $V_{B t}$ and $V_{U C}$. Current increases with a slope of $V_{B t} / L_{1}$ and $V_{U C} / L_{2}$ respectively as demonstrated in Fig. 4. At the end of this interval, switch $S_{3}$ is turned off providing freewheeling path for $i_{L 1}$ through $D_{4}$. In interval $T_{3}$, switch $S_{4}$ is switched-on in order to avoid voltage drop across the diode $D_{4}$ while inductor $L_{2}$ continues to charge from the ultracapacitor. Switches $S_{2}$ and $S_{5}$ are turned off at the end of interval $T_{3}$, forcing current to flow through anti-parallel diodes of their corresponding complementary switches. Energy stored in the inductors $L_{1}$ and $L_{2}$ are transferred to the dc link through diode $D_{1}$ resulting in a voltage drop of $1 \mathrm{~V}-1.2 \mathrm{~V}$. This voltage drop is reduced to the level of around $0.2 \mathrm{~V}$ by gating on switch $S_{1}$ to act as synchronous rectifier. At the end of this interval, gating signals for each switching leg are complemented to start charging the inductors $L_{1}$ and $L_{2}$ going back to interval $T_{1}$.

Current through and voltage across the inductors under steady state operation is given in Fig. 3. Applying voltsec balance for both the inductors, relation between the three voltages are given by (7) and (8).

$$
\begin{gathered}
V_{B t}=\frac{T_{4}+T_{5}}{T_{1}} \cdot V_{d c}=\frac{d_{2} T_{S}}{d_{1} T_{S}} \cdot V_{d c}=\frac{d_{2}}{d_{1}} \cdot V_{d c} \\
V_{U C}=\frac{T_{4}+T_{5}}{T_{1}+T_{2}+T_{3}} \cdot V_{d c}=\frac{d_{2} T_{S}}{T_{S}-d_{2} T_{S}} \cdot V_{d c}=\frac{d_{2}}{1-d_{2}} \cdot V_{d c}
\end{gathered}
$$

Where, $d_{1}$ is the ratio of on-time of switch $S_{3}$ to total switching period $T_{S}$ and similarly $d_{2}$ corresponds to switch $S_{2}$. From (8), it can be observed that the $d_{2}$ can be calculated for a required boost ratio of $V_{U C}$ to $V_{d c}$. Since the ultracapacitor voltage is assumed to be smaller than $V_{d c}$, the duty ratio $d_{2}$ is being functioned always below 0.5 with the voltage gain defined as $M_{2}$. Variation in $M_{2}$ for change in $d_{2}$ between 0 and 0.5 is as shown in Fig. 6 . On the other hand, the switch $S_{3}$ can be controlled with a duty ratio between 0 to $\left(1-d_{2}\right)$ in order to boost the battery voltage to dc link. The gain $M_{1}$ connecting $V_{B t}$ and $V_{d c}$ is given in (9).

$$
M_{1}=\frac{V_{B t}}{V_{d c}}=\frac{d_{2}}{d_{1}} ; \quad M_{2}=\frac{V_{U C}}{V_{d c}}=\frac{d_{2}}{1-d_{2}} ;
$$

For a given value of $d_{2}$, the minimum voltage gain $M_{1}$ can be obtained considering maximum value of duty ratio $d_{1}$. It is clear from Fig. 4 that the maximum value of the boost ratio for the battery to dc link cannot exceed the boost ratio of the ultracapacitor to the dc link. Hence, this switching sequence can be employed only if $V_{B t}$ is higher than $V_{U C}$. However, switching sequence corresponds to the switching legs of battery and ultracapacitor needs to be interchanged if $V_{U C}$ is higher than $V_{B t}$. With the proposed converter it is possible to transfer energy from two sources of unequal voltage by independently controlling the share from each.
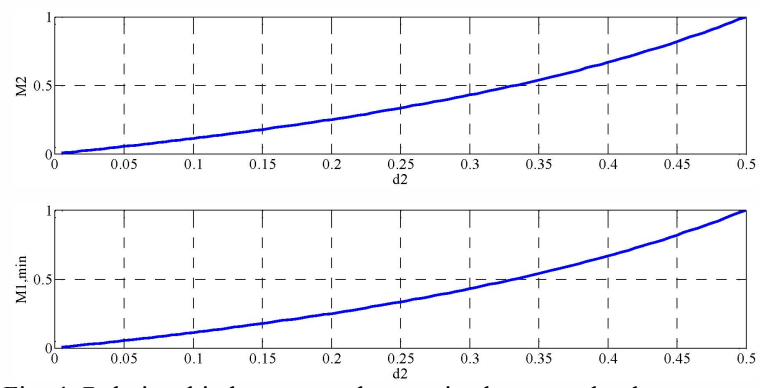

Fig. 4. Relationship between voltage gains between the three sources for mode D.

The proposed converter can be either voltage or current controlled, depending on the role of source in the overall system and their constraints. Total power required from the auxiliary sources can be shared between the battery system and the ultracapacitor bank based on factors like, charging current limitations of battery, state of charge (SOC), dynamics of the converter, etc.

\section{E. Dc Link to Both Battery and Ultracapacitor}

Kinetic energy stored in the traction drive is fed back to the source during regenerative braking operation. Since, a fuel cell stack lacks bidirectional power handling capability; battery bank plays an important role. During sudden braking condition, regenerative power can be much higher than the battery can absorb. Additional energy which battery cannot capture is utilized in charging ultracapacitor, which has higher power density as compared to battery. Switching sequence during this mode of operation is given in mode E of Table 2. In this mode of operation, $L_{2}$ is always connected to the ultracapacitor by keeping $S_{5}$ and $S_{6}$ in ON and OFF state respectively throughout the cycle. The switch pairs $S_{1}-S_{2}$ and $S_{3}-S_{4}$ are operated in complementary fashion with duty ratios of $d_{1}$ and $d_{2}$ as shown in Fig. 8 where $d_{2}$ is greater than $d_{1}$.

Switches $S_{1}, S_{3}$ and $S_{5}$ are turned-on in the time interval $T_{1}$ transferring energy from the dc link to charge both the auxiliary sources. Inductor currents $i_{L 1}$ and $i_{L 2}$ increase as $V_{d c}$ appears at point A. At the end of $T_{1}$, switch $S_{1}$ is turned-off providing free wheeling path for the inductor currents through diode $D_{2}$. In order to reduce 
the voltage drop across the diode, switch $S_{2}$ is gated ON to effectively function as a synchronous rectifier in $T_{3}$. In order to control the charging of two sources independently, switch $S_{3}$ is turned-off and $S_{4}$ is turned-on maintaining the current through inductor $L_{1}$ as shown in Fig. 5. During this time interval, the inductor current $i_{L 2}$ continues to charge the. Switches $S_{2}$ and $S_{4}$ are turned-off at the end of the interval $T_{4}$. Current in inductors flow from dc link to battery and ultracapacitor through switches $S_{1}, S_{5}$ and diode $D_{3}$. One cycle of operation completes when the switch $S_{3}$ is turned on providing path for $i_{L 1}$ by reducing the voltage drop across it.

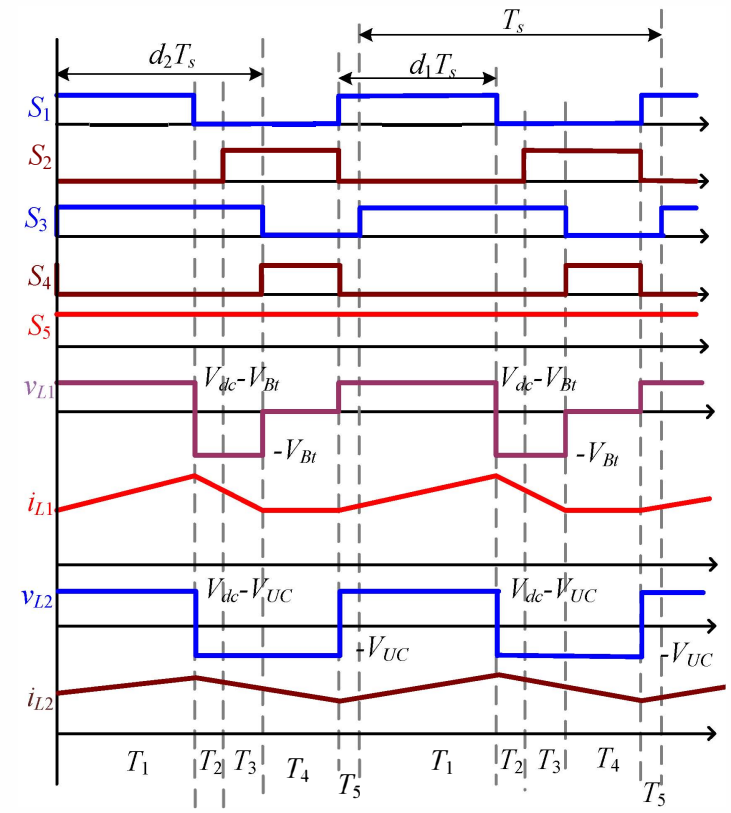

Fig. 5. Steady-state waveforms for mode E.

Relationship between the three voltage sources can be derived by applying volt-sec balance across the inductors, which has been demonstrated in Fig. 5.

$$
\begin{gathered}
V_{B t}=\frac{T_{1}+T_{5}}{T_{1}+T_{2}+T_{3}+T_{5}} \cdot V_{d c}=\frac{T_{1}+T_{5}}{T_{S}-T_{4}} \cdot V_{d c}=\frac{d_{1}}{d_{2}} \cdot V_{d c} \\
V_{U C}=\frac{T_{1}+T_{5}}{T_{S}} \cdot V_{d c}=d_{1} \cdot V_{d c}
\end{gathered}
$$

The ultracapacitor voltage $V_{U C}$ is controlled by varying $d_{1}$, which is related by (11). Energy transferred to the battery is regulated by changing the variable $d_{2}$ for a given value of $d_{1}$. Voltage gain functions for both the voltage sources are defined and are obtained as,

$$
M_{1}=\frac{V_{U C}}{V_{d c}}=d_{1} ; \quad M_{2}=\frac{V_{B t}}{V_{d c}}=\frac{d_{1}}{d_{2}} ;
$$

Fig. 6 shows the variation of voltage gain $M_{1}$ with respect to duty ratio $d_{1}$, which is a linear function. However, the voltage gain for battery i.e. $M_{2}$ is a function of both $d_{1}$ and $d_{2}$ that can be changed by varying value of $d_{2}$ from 0 to $\left(1-d_{1}\right)$. For a given value of $d_{1}$, minimum gain is obtained at a duty ratio of $\left(1-d_{1}\right)$ which is shown in Fig. 6. When both the auxiliary source voltages are less than dc link voltage, it is clear that the duty ratio $d_{1}$ has to be less than 0.5 . Moreover, $V_{B t}$ needs to be higher than $V_{U C}$ for this specific switching sequence. Otherwise,
$S_{3}$ has to be kept on while switching $S_{5}-S_{6}$ at a duty ratio of $d_{2}$.
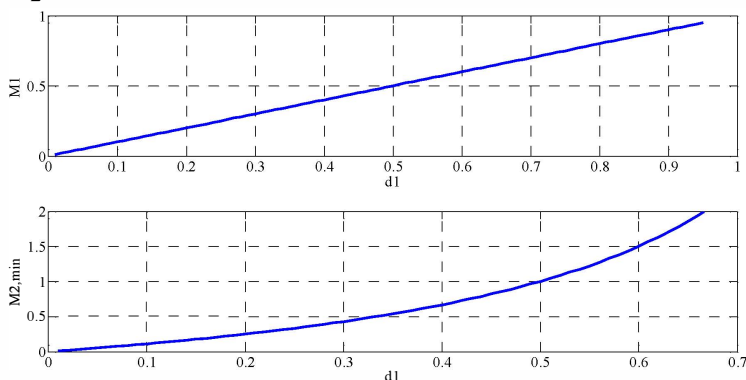

Fig. 6. Relationship between voltage gains between the three sources for mode $\mathrm{E}$.

\section{DESIGN OF THE CONVERTER}

For grid tied applications, it is assumed that a battery bank is required to support full power until ancillary sources can reach full power and/or peak efficiency. Similarly, during times when the auxiliary source needs to be reduced, excess energy can be stored into the battery bank. For a $5 \mathrm{~kW}$ power converter, a battery bank of $144 \mathrm{~V}, 17 \mathrm{Ah}$ will provide a maximum continuous current of at least $51 \mathrm{~A}$, providing a runtime of 30 minutes. Coupling this system with an ultracapacitor bank rated at $125 \mathrm{~V}, 15 \mathrm{~F}$ provides an additional 20 seconds of high power runtime for quick power bursts where the battery may not need to be engaged. The results of the operation of this grid-tied converter are presented in the following section.

In most practical systems, a traction motor, or grid-tied connection, is driven by a voltage source inverter (VSI) with a constant dc link voltage. A fixed voltage of $300 \mathrm{~V}$ is chosen. The proposed converter can be built from a standard three-phase inverter by connecting three sources namely $V_{d c}, V_{B t}$ and $V_{U C}$ to collector terminal of the top switches. Two inductors are inserted between midpoints of the three switching legs. Hence, it is very easy to construct the proposed converter without modifying driver part of the inverter. Values of inductors are designed to limit ripple current to a specific amount for a given switching frequency. Similarly capacitance at the dc link is also designed based on the allowed value of ripple in $V_{d c}$ and switching currents.

\section{RESULTS}

The proposed multiple-input dc-dc converter has been tested in various modes of operation discussed in previous section. For validation purpose, the following specifications are taken. $V_{d c}=300 \mathrm{~V}$, output power $P_{o}=$ $5 \mathrm{~kW}$, switching frequency of $20 \mathrm{kHz}$. The details are as follows:

1. Battery bank: $144 \mathrm{~V}, 17 \mathrm{Ah}$ Lithium-ion battery bank, voltage varies from $120 \mathrm{~V}$ to $140 \mathrm{~V}$, series resistance of $30 \mathrm{~m} \Omega$.

2. Ultracapacitor tank: $125 \mathrm{~V}, 15 \mathrm{~F}$, parasitic inductance of $10 \mu \mathrm{H}$, series resistance of $18 \mathrm{~m} \Omega$.

3. Dc link capacitor: $3 \mathrm{mF}$

4. Inductors: $0.75 \mathrm{mH}$ each. 
5. The switches are controlled from DSP320F2808.

The above specified system has been implemented in a 'Typhoon HIL-400' Hardware-In-Loop (HIL) system to validate the analysis and performance of the system. The HIL real-time emulator comprises of an applicationspecific processing architecture based on a FPGA with fast analog/digital input and output interfaces with a supporting front-end software tool-chain performing the function of power electronics and energy storage systems like battery and ultracapacitors. With the minimum step time of $0.5 \mu \mathrm{s}$ and ultra-low latency of $1 \mu \mathrm{s}$, most of the experiments of power electronics and drives having switching frequency up to $50 \mathrm{kHz}$ can be emulated. Accuracy and latency of HIL has been proved for various complex systems like grid-connected inverter [11]. Control of the semiconductor devices is being executed externally at a constant switching frequency of $20 \mathrm{kHz}$ using DSP.

In order to verify the analysis, the proposed converter is tested for different modes of operation explained in Section II and results are presented in Fig. 7 to Fig. 14. In mode A(i), energy is transferred from the battery to dc link shown in Fig. 7. $V_{B t}$ of $130 \mathrm{~V}$ is boosted to $V_{d c}$ of $300 \mathrm{~V}$ to supply the grid load by transferring energy through inductor $L_{1}$. Positive current of $i_{d c}$ indicates the current flowing into dc link capacitor from the MIPC and similarly positive value of $i_{B t}$ shows discharge current of the battery. A smooth current of around 70A with small ripple is flowing through $L_{1}$ maintaining zero current from the ultracapacitor, which can be seen in $i_{L 2}$. For power flow from dc link to the battery, experimental results are shown in Fig. 8. A negative current of approximately 20A through $L_{1}$ shows reversal of direction of flow with zero current flowing through $L_{2}$ and hence through ultracapacitor. Voltages across the switches $S_{2}$ and $S_{4}$ show dc link voltage and battery voltage respectively along with their states. Whenever, $S_{1}$ is ON, voltage $V_{d c}$ appears across the switch $S_{2}$ which can be observed in waveform of $V_{S 2}$. Similarly $V_{d c}$ appears across $S_{4}$ when $S_{3}$ is gated on for the duration of $(1-D) T_{S}$. Peak to peak ripple current of $5 \mathrm{~A}$ in $L_{1}$ validates the design selection of the inductors.

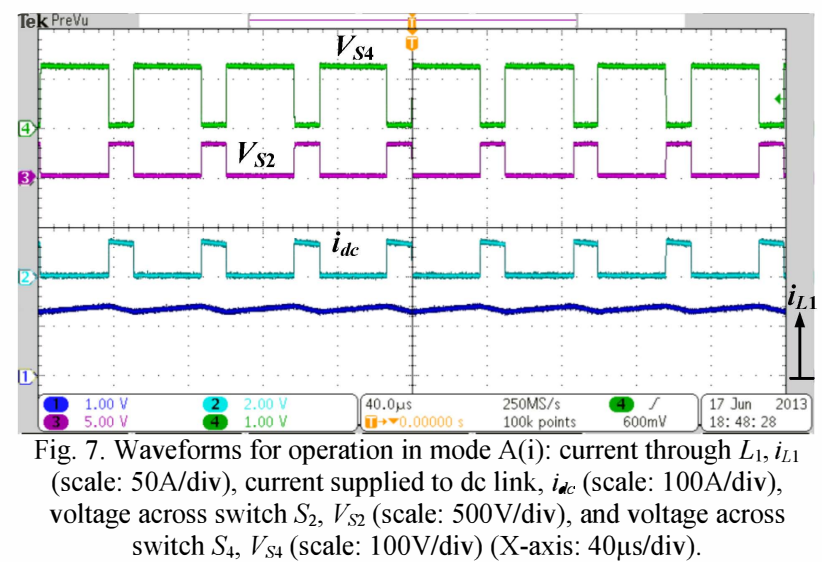

Likewise, waveforms for transfer of energy from the ultracapacitor to the dc link are presented in Fig. 9. It is clear from the figures that voltage $V_{U C}$ is being boosted to
$V_{d c}$ by transferring current through $L_{2}$ maintaining zero current from the battery. Power flow control of each sources are possible without affecting the remaining sources. Since voltage across the ultracapacitor varies during discharge, current drawn from the ultracapacitor needs to be regulated by inclusion of closed loop control to vary the duty ratio based on the feedback information of current. Charging of the ultracapacitor from the dc link is performed by using switching sequence given in mode B(ii) and corresponding results are presented in Fig. 10. Current is fed from the dc link, hence negative waveform is seen in Fig. 10 along with the negative current $i_{L 2}$ charging the ultracapacitor tank.

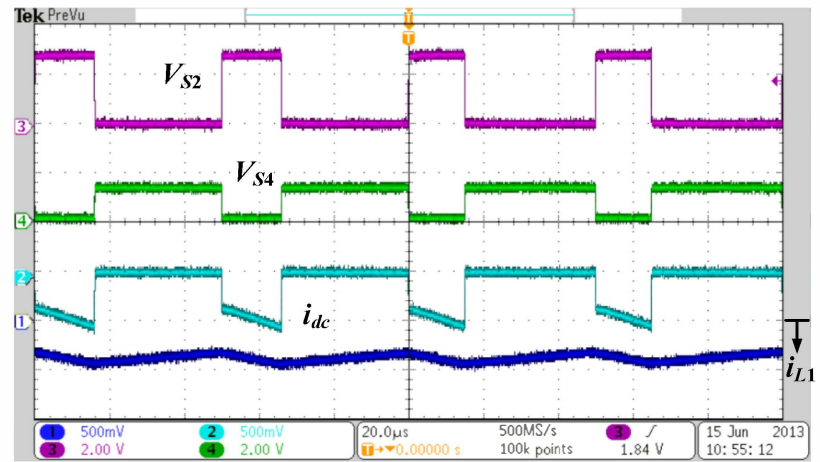

Fig. 8. Waveforms for operation in mode A(ii): (a) current through $L_{1}$ $i_{L 1}$ (scale: $25 \mathrm{~A} / \mathrm{div}$ ), current supplied to dc link, $i_{\mathrm{dc}}$ (scale: $25 \mathrm{~A} / \mathrm{div}$ ), voltage across switch $S_{2}, V_{S 2}$ (scale: $200 \mathrm{~V} / \mathrm{div}$ ), and voltage across switch $S_{4}, V_{S 4}$ (scale: $200 \mathrm{~V} / \mathrm{div}$ ) (X-axis: $\left.20 \mu \mathrm{s} / \mathrm{div}\right)$.

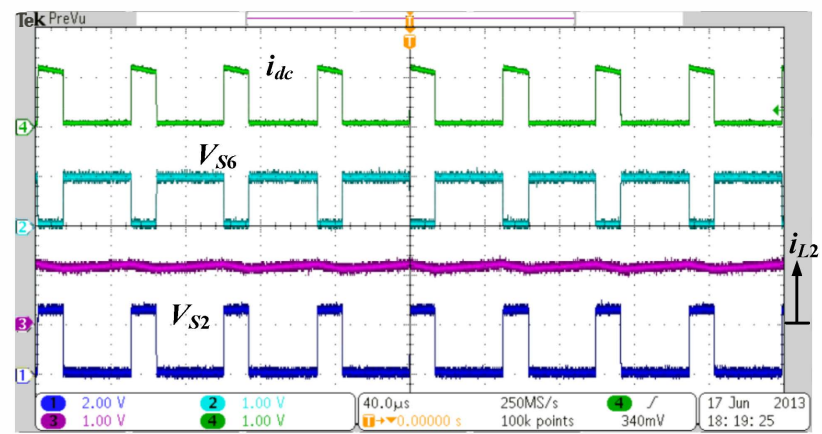

Fig. 9. Waveforms for operation in mode B(i): (a) voltage across switch $S_{2}, V_{S 2}$ (scale: $200 \mathrm{~V} / \mathrm{div}$ ), voltage across switch $S_{6}, V_{S 6}$ (scale: $100 \mathrm{~V} / \mathrm{div}$ ), current through $L_{2}, i_{L 2}$ (scale: $50 \mathrm{~A} / \mathrm{div}$ ), and current flowing into dc link, $i_{d c}$ (scale: $\left.50 \mathrm{~A} / \mathrm{div}\right)$ (X-axis: $\left.40 \mu \mathrm{s} / \mathrm{div}\right)$.

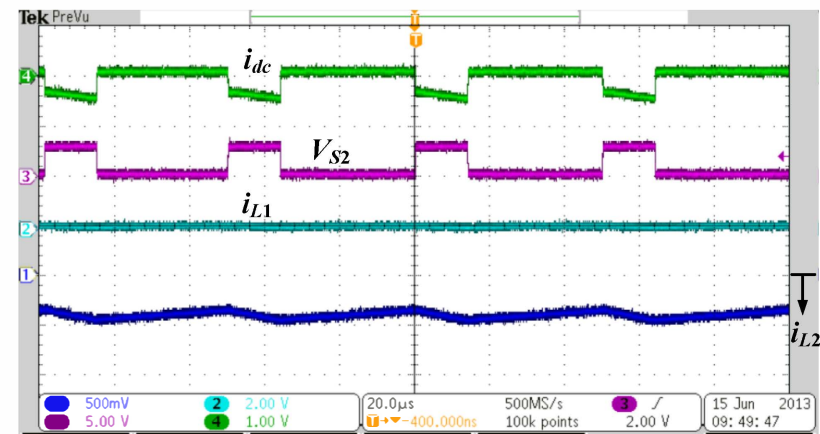

Fig. 10. Waveforms for operation in mode B(ii): (a) current through $L_{2}$, $i_{L 2}$ (scale: $25 \mathrm{~A} / \mathrm{div}$ ), current through $L_{1}, i_{L 1}$ (scale: $100 \mathrm{~A} / \mathrm{div}$ ), voltage across switch $S_{2}, V_{S 2}$ (scale: $500 \mathrm{~V} / \mathrm{div}$ ), and current flowing from dc link, $i_{d c}$ (scale: $\left.50 \mathrm{~A} / \mathrm{div}\right)(\mathrm{X}$-axis: $20 \mu \mathrm{s} / \mathrm{div})$.

Fig. 11 shows results for transfer of energy from the battery bank to the ultracapacitor. Waveform of $V_{S 4}$ 
demonstrates the voltage across the switch $S_{4}$. Top and bottom switches in each leg are operated complementary to each other and top switch of one leg is switched with bottom switch of another leg. Whenever switch $S_{3}$ and $S_{6}$ are ON, battery voltage $V_{B t}$ appears across switch $S_{4}$ and inductor current is getting charged from the battery. Ripple in $i_{L 1}$ or $i_{L 2}$ have reduced by half since the two inductors are in series in this mode of operation. Dynamic behavior of the converter in mode C(i) is presented in Fig. 11. Operating converter in a fixed duty ratio inductor current increases initially to charge the ultracapacitor and reduces the charging rate once it has reached the specific voltage. Negative current in $L_{2}$ implies charging of the ultracapacitor. Pulsating current flowing from the battery is also given which has envelope similar to waveform of $i_{L 2}$ but with opposite polarity.

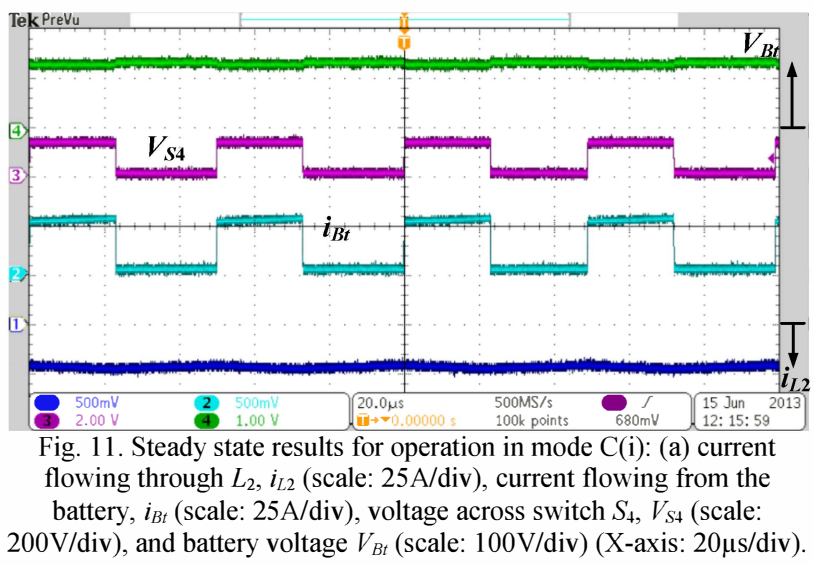

Functioning of the converter in mode C(ii) is same as that of mode $\mathrm{C}$ (i) except variation in duty ratio according to the voltages $V_{B t}$ and $V_{U C}$ to reverse the direction of current flow from the ultracapacitor to the battery as shown in Fig. 12.

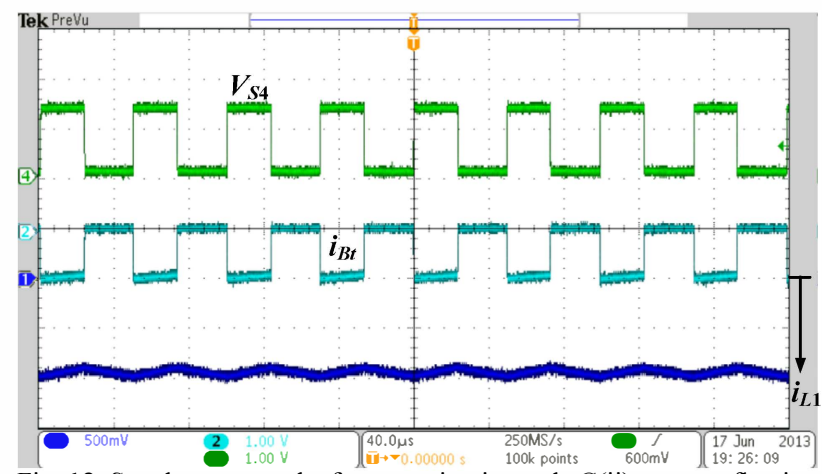

Fig. 12. Steady state results for operation in mode C(ii): current flowing through $L_{1}, i_{L 1}$ (scale: $25 \mathrm{~A} / \mathrm{div}$ ), current transferred to the battery, $i_{B t}$ (scale: $50 \mathrm{~A} / \mathrm{div}$ ), and voltage across switch $S_{4}, V_{S 4}$ (scale: $\left.200 \mathrm{~V} / \mathrm{div}\right)(\mathrm{X}$ axis: $40 \mu \mathrm{s} / \mathrm{div}$ )

In mode $\mathrm{D}$, both the auxiliary sources are transferring energy to the dc link to drive the traction motor. Two sources with different voltage levels are boosting voltage to $V_{d c}$ by switching all the devices as explained in Section II. Switch pair $S_{2}-S_{5}$ is gated with the same signal of duty ratio $d_{2}$ with complementary signal given to switches $S_{1}$ $S_{6}$. When $S_{3}$ and $S_{5}$ are turned on, inductors $L_{1}$ and $L_{2}$ are storing energy supplied from the battery and the ultracapacitor respectively as shown in Fig. 13(a). Switch $S_{3}$ is turned-off maintaining current $i_{L 1}$ for a short time before turning $S_{1}$ and $S_{6}$ to ON state. Since $V_{d c}$ and $V_{U C}$ are of same order, difference between the duty ratios $d_{1}$ and $d_{2}$ is very small. Energy is transferred to the dc link whenever switch $S_{1}$ is turned-on. The current flowing into the dc link capacitor, $i_{d c}$ can be observed when $V_{d c}$ appears across switch $S_{2}$. Fig. 13(b) shows peak value of $i_{d c}$ is sum of $i_{L 1}$ and $i_{L 2}$ indicating that the energy transferred to dc link is resultant of both the auxiliary sources.

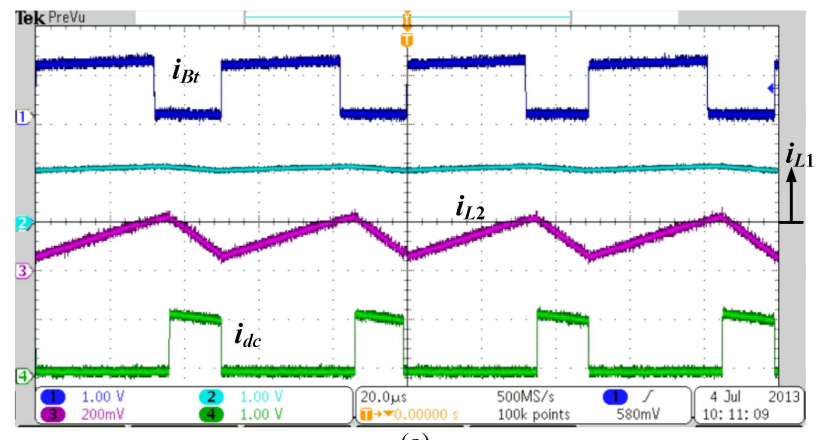

(a)

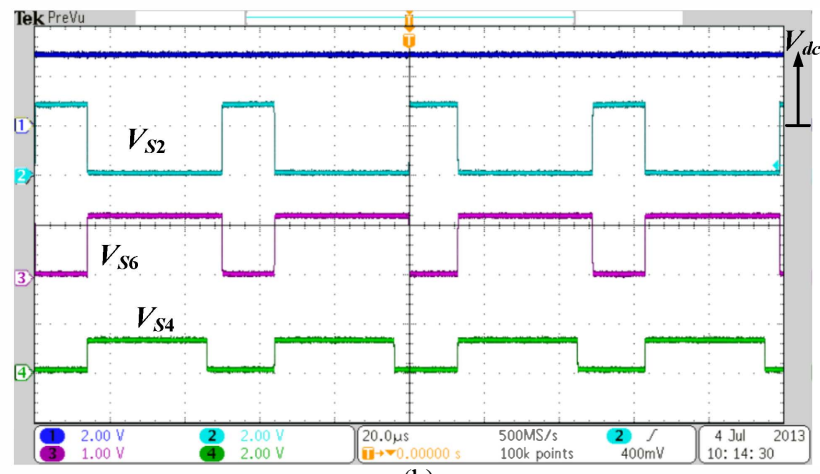

$$
\text { (b) }
$$

Fig. 13. Steady state results for operation in mode D: (a) current flowing from the battery, $i_{B t}$ (scale: $50 \mathrm{~A} / \mathrm{div}$ ), current through $L_{1}, i_{L 1}$ (scale: $50 \mathrm{~A} / \mathrm{div}$ ), current through $L_{2}, i_{L 2}$ (scale: $10 \mathrm{~A} / \mathrm{div}$ ), and current flowing into dc link, $i_{d c}$ (scale: 50A/div) (X-axis: $20 \mu \mathrm{s} / \mathrm{div}$ ), (b) dc link voltage, $V_{D C}$ (scale: $200 \mathrm{~V} / \mathrm{div}$ ), voltage across switch $S_{2}, V_{S 2}$ (scale: $200 \mathrm{~V} / \mathrm{div}$ ), voltage across switch $S_{6}, V_{S 6}$ (scale: $100 \mathrm{~V} / \mathrm{div}$ ), and voltage across switch $S_{4}, V_{S 4}$ (scale: $\left.200 \mathrm{~V} / \mathrm{div}\right)$ (X-axis: $20 \mu \mathrm{s} / \mathrm{div}$ ).

Energy is being restored back to the battery and the ultracapacitor from dc link during regenerative braking. Since the battery voltage $V_{B t}$ is higher than the ultracapacitor voltage $V_{U C}$ in this example, switch $S_{5}$ is maintained in $\mathrm{ON}$ state throughout this mode of operation, while switches $S_{1}$ and $S_{3}$ are being switched with duty ratio of $d_{1}$ and $d_{2}$ respectively. Voltage across $S_{2}$ and $S_{4}$ shown in Fig. 14(a) demonstrates unequal duty ratio in order to pump in regenerative energy to auxiliary sources of uneven voltages. Current through $L_{2}$ is also shown in the figure, which is same as current flowing into the ultracapacitor. Fig. 14(b) shows waveform of current supplied from dc link $i_{d c}$ and charging current of battery $i_{B t}$ along with the voltage across ultracapacitor $V_{U C}$. 


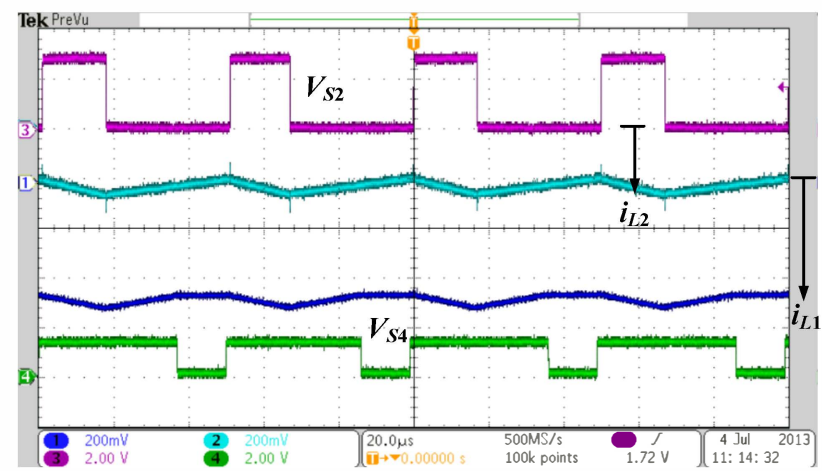

(a)

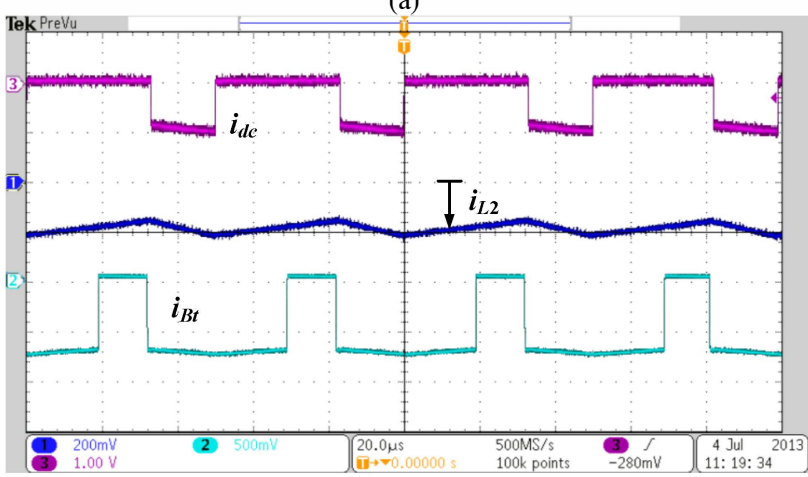

(b)

Fig. 14. Steady state results for operation in mode E: (a) current through $L_{1}, i_{L 1}$ (scale: $10 \mathrm{~A} / \mathrm{div}$ ), current through $L_{2}, i_{L 2}$ (scale: $10 \mathrm{~A} / \mathrm{div}$ ), voltage across switch $S_{2}, V_{S 2}$ (scale: $200 \mathrm{~V} / \mathrm{div}$ ), and voltage across switch $S_{4}, V_{S 4}$ (scale: $200 \mathrm{~V} / \mathrm{div}$ ) (X-axis: $20 \mu \mathrm{s} / \mathrm{div}$ ), (b) current flowing through $L_{2}, i_{L 2}$ (scale: $10 \mathrm{~A} / \mathrm{div}$ ), charging current flowing into the battery, $i_{B t}$ (scale: $25 \mathrm{~A} / \mathrm{div}$ ), and current transferred from dc link, $i_{d c}$ (scale: $\left.50 \mathrm{~A} / \mathrm{div}\right)(\mathrm{X}-$ axis: $20 \mu \mathrm{s} / \mathrm{div})$

Emulation results shown here validate the proposed multiple-input DC-DC bidirectional converter topology. It can be observed that the experimental waveforms coincide well with the analytically predicted steady-state operating waveforms. Though the results have been emulated using hardware-in-the-loop real-time system for verification of the proposed converter, this can be applied to practical system finding applications in electric vehicles, smart-grid, and distributed energy resources. In this paper, an application for fuel cell hybrid electric vehicle has been demonstrated. However, the proposed topology can be applied to different applications where more than two dc sources of unequal voltage levels need to transfer energy between themselves. This can also be used in charge balancing of multiple battery banks.

\section{SUMMARY AND CONCLUSION}

This paper proposes a multiple-input bidirectional dcdc converter to interface more than two sources of different voltage levels. The converter can be operated either in buck mode or boost mode in either direction of power flow. It is possible to control power flow between each pair of sources independently when more than two sources are active. The major advantage of the proposed topology is that it can be built from a standard threephase inverter with few changes in connections.

This paper gives detailed analysis, modulation and operation of the converter for various modes. In each mode, relationship between the sources are derived which assists in implementation of the controller. Design of the converter for a typical hybrid fuel cell vehicle has been explained where dc-link of the inverter, lithium-ion battery bank and ultracapacitor tank are being interfaced together. Typhoon based hardware-in-the-loop (HIL) real-time system has been used to emulate the designed converter to validate the performance. Results obtained from this system have been presented and match very well with the analytically expected waveforms. This converter not only finds application in fuel cell vehicles, this can be utilized in DER, smart and micro grid, battery management systems etc. where more than two dc sources need to be interfaced with bidirectional power flow capability.

\section{REFERENCES}

[1] C. Zhao, S. D. Round, and J. W. Kolar, "An isolated threeport bidirectional dc-dc converter with decoupled power flow management", IEEE Trans. on Power Electronics, vol. 23 , no. 5 , pp. 2443-2453, Sept. 2008.

[2] H. Tao, J. L. Duarte, M. A. M. Hendrix, "Three-port triplehalf-bridge bidirectional converter with zero-voltage switching", IEEE Trans. on Power Electronics, vol. 23, no. 2, pp. 782-792, Mar. 2008.

[3] S. Liu, X. Zhang, H. Guo, and J. Xie, "Multiple input bidirectional dc/dc converter for energy supervision in fuel cell electric vehicles", in Proc. IEEE International conference on Electrical and Control Engineering, 2010, pp. 3890-3893.

[4] H. Matsuo, W. Lin, F. Kurokawa, T. Shigemizu, and N. Watanabe, "Characteristics of the multiple-input dc-dc converter", IEEE Trans. on Industrial Electronics, vol. 51, no. 3, pp. 625-631, Jun. 2004.

[5] W-S. Liu, J-F. Chen, T-J. Liang, R-L. Lin, and C-H. Liu, "Analysis, design, and control of bidirectional cascoded configuration for a fuel cell hybrid power system", IEEE Trans. on Power Electronics, vol. 25, no. 6, pp. 15651575, Jun. 2010.

[6] W. Jiang, and B. Fahimi, "Multiport power electronic interface- concept, modeling, and design", IEEE Trans. on Power Electronics, vol. 26, no. 7, pp. 1890-1900, Jul. 2011.

[7] L. Solero, A. Lidozzi, and J. A. Pomilio, "Design of multiple-input power converter for hybrid vehicles", IEEE Trans. on Power Electronics, vol. 20, no. 5, pp. 10071006, Sept. 2005.

[8] L. Solero, A. Lidozzi, and J. A. Pomilio, "Design of multiple-input power converter for hybrid vehicles", in Proc. IEEE APEC, 2004, vol. 2, pp. 1145-1151.

[9] F. Z. Peng, M. Shen, and K. Holland, "Application of Zsource inverter for traction drive of fuel cell- battery hybrid electric vehicles", IEEE Trans. on Power Electronics, vol. 22, no. 3, pp. 1054-1061, May 2007.

[10] K. Rajashekara, and J. G. Noetzel, "Power system to transfer power between a plurality of power sources", US Patent 7084525 B2, August 1, 2006.

[11] Z. R. Ivanovic, E. M. Adzic, M. S. Vekic, S. U. Grabic, N. L. Celanovic, and V. A. Katic, " HIL evaluation of power flow control strategies for energy storage connected to smart grid under unbalanced condition", IEEE Trans. on Power Electronics, vol. 27, no. 11, pp. 4699-4710, Nov. 2012. 